measures that are needed. . . . It is far more realistic for doctors and for government to admit to patients that resources are indeed limited and to promote sensible discussion on the most compassionate and most economic distribution of resources." That is the quality of contribution that epitomised this ARM and that contributes to making the BMA a potent force in the political arena. It exemplified the chairman of council's earlier remarks during the main nuclear warfare debate: "When the association speaks on medical issues its authority is unchallenged. When it strays from medical issues it does so at its peril. . . . Our authority is diminished in the eyes of the general public and of our members." A thoughtful comment at a thoughtful annual meeting that should be a lesson for future gatherings of the BMA's representative body.

${ }^{1}$ British Medical Association. The medical effects of nuclear war. Chichester: John Wiley \& Sons, 1983.

2 Anonymous. Doctors and the bomb. Br Med f 1983;286:823.

${ }^{3}$ Anonymous. Nuclear war: review of medical effects and civil defence. Br Med F $1981 ; 283: 256$.

\section{An Institute of Health}

Does Britain need an institute of health, similar in authority and influence to the Institute of Medicine in the United States? This concept has been discussed in medical circles for several years now, ${ }^{12}$ but last week a practical initiative was made when the King Edward's Hospital Fund for London brought together a group of leading doctors, civil servants, and academics for an afternoon of informal discussion.

Without doubt, they agreed, there is a gap. Britain has no body drawing on medical, economic, and sociological skills which can analyse health policy, examine priorities, and act as a non-governmental pressure group for health in its widest sense. Nor is there any multidisciplinary source of objective, scientifically authoritative advice on issues such as diet and health. either for the government or for the various professional groups working within the National Health Service.

Attempts at the meeting to put flesh on to the skeletal concept of an institute proved rather more difficult. All agreed that the body should be multidisciplinary-but how far the net should be cast was less clear. Should trades unions, employers' groups, and patient self help associations be included in the membership as well as the royal colleges and other comparable institutions? Experience from the pastnotably the Central Health Services Council-showed that members of an institute would have to serve as individuals rather than as representatives if useful, realistic decisions were to be reached. Furthermore, independence of the government was seen as essential if the institute was to remain free not only to formulate advice unacceptable to ministers but also to publish that advice and campaign for it.

For practical reasons, and perhaps because experience had convinced them that size has a deadening effect on institutions, everyone seemed agreed that the new body should have only a few full time staff. But small size would necessarily limit the range of functions that the institute could undertake-and here there was less agreement, with support for many different functions.

Firstly, the proposed institute could concentrate on policy analysis and health services research-looking at what had gone wrong in the past, what was happening now, and what should be done in the future. Existing academic units, with their heavy emphasis on research, are amassing vast amounts of data on the health service, but much less time is being given to critical, thoughtful analysis of these data-partly because funds are more readily available for research than for analysis. Some sort of independent voice is needed on issues such as the links between the private and public sectors of health care.

Secondly, the institute could function as a multidisciplinary pressure group, mobilising opinion from many professional and non-professional sources in support of health policies that have already been agreed. Such an institute might persuade governments to take more account of the health implications of their decisions-for example, on taxation or agriculture.

Thirdly, the institute could be seen as a prestigious and influential source of objective scientific advice on health matters. Already, however, the Conference of Royal Colleges and Faculties has established a reputation as a consensus building body on contentious subjects such as brain death: if the conference were given some full time staff it could expand its activities.

Another valuable task for an independent, authoritative body in the 1980 s might be in attempting to provide some guidance on the immense range of policy questions for which answers will be needed at a time of zero growth. Conversely, in a time of economic recession one aspect of their plans that the advocates of an institute should remember is that the money needed to run it could have been used for other purposes.

Perhaps some sort of institute has a wide psychological appeal simply because so many medical controversies remain "controversial" long after they should have been settled (pertussis vaccine, fluoride) while others remain undecided from lack of evidence to convince the sceptics (fats and coronary heart disease). If an institute could help speed public acceptance of the medical consensus on such issues as well as encourage public awareness of the need for tougher action on tobacco and alcohol then its public relations function would certainly be worth while-but like the oracles of the ancient world its authority would have to be unchallengeable. That in turn might lead its members to excessive caution in reaching decisions so long as any substantial fraction of scientific opinion remained unconvinced by the majority argumentsthough the consensus statements produced by the National Institutes of Health have not lacked vigour.

At this stage more thought is needed. As a first step the Conference of Royal Colleges and Faculties might be given more tasks and more staff. The BMA's Board of Science, too, has shown with its report on nuclear war ${ }^{3}$ that it can produce a detailed analysis of medical issues that is accepted as authoritative. Purely medical questions can, indeed, usually be answered within the profession. That conclusion strengthens the arguments for an institute whose main practical task might be finding ways to convert consensus policies on health into effective action at community level. Or should the emphasis be given to an academic, policy analysis unit, trying to produce wisdom from the mass of information generated by research teams and acting as a monitor and commentator on the nation's health ?

Possibly the proponents of the various models might be asked to suggest specific questions that might be put to a newly formed institute. What are the uncertainties in health for which an authoritative answer is possible (based on sound evidence) and for which the answer is likely to be of immediate practical 
value and importance? Once the questions are identified it may be easier to choose the forum in which to answer them.

TONY SMITH

Deputy Editor,

$B M f$

${ }^{1}$ Anonymous. Does Britain need an academy of medicine? $\mathrm{Br}$ Med $\mathcal{F}$ $1979 ;$ ii : 1611

Godber G. An institute of health ? The Times Health Supplement 1982 Feb 19:9 (col 1-4).

${ }^{3}$ British Medical Association. The medical effects of nuclear war. The report of the British Medical Association's Board of Science and Education. Chichester: John Wiley and Sons, 1983.

\section{Asbestos related diseases without asbestosis}

Asbestosis and mesothelioma are prescribed diseases under the Industrial Injuries Scheme and entitle the patient or his dependants to compensation. The term asbestosis should be used only to denote fibrosis within the lungs. The three other non-malignant conditions associated with exposure to asbestos are pleural plaque, pleural effusion, and diffuse pleural thickening. The Industrial Injuries Council now recommends that, when it reaches a certain extent, the last of these should also be prescribed. ${ }^{1}$

Pleural plaques develop in the parietal pleura, seldom cause disability, and are not to be prescribed. Pleural effusions may be transient but some are chronic and may recur. ${ }^{2}$ No prescription is proposed for these, but, under the new proposals, if they cause sufficient bilateral thickening of the pleura an application to a pneumoconiosis medical panel would lead to certification.

Diffuse pleural thickening associated with exposure to asbestos has become increasingly recognised. ${ }^{34}$ Both pleural layers are affected and restrict the expansion of the lung. Histological examination shows only non-specific fibrosis, and, as with effusions, the diagnosis depends on excluding other causes such as tuberculosis and other infections, collagen diseases, trauma, chronic uraemia, and drug induced fibrosis. ${ }^{5}$ With such exclusions, the Industrial Injuries Council is satisfied that bilateral diffuse pleural thickening in asbestos workers is likely to be industrial and recommends that disablement benefit should be awarded when the thickening is bilateral, is over $5 \mathrm{~mm}$ thick, and extends over more than a quarter of the chest wall.

The prescription of this condition will be welcomed, though some may be dissatisfied that the disease has to be so extensive to allow certification. Nevertheless, the committee suggests that this requirement should be reviewed in the light of experience.

The report also considers cancer of the lung in asbestos workers. At present this condition is not prescribed, but when it occurs in association with asbestosis it is considered to be a sequel and benefit is payable. Claims which have been rejected during life may be successful after death because necropsy may disclose previously undiagnosable mild asbestosis. The council now recommends prescription of lung cancer in patients with asbestosis and in certain other circumstances. In doing so it had to consider how to take account of smoking habits and the amount of exposure which would justify certification. The problem of the contribution of smoking to lung cancer in asbestos workers has been disposed of neatly. Studies in the
United States in insulation workers have shown that the $\mathbb{}$ relative risks of developing lung cancer are: non-exposed non-smokers 1 ; asbestos exposed non-smokers 5; non-exposed smokers 11 ; asbestos exposed smokers $53 .{ }^{6}$ Because exposure increases the risk by a factor of five in both smokers and non-smokers the council recommends that smoking should be disregarded.

Cancer of the lung in asbestos workers may be divided into two broad types. Firstly, peripheral adenocarcinoma, which is unrelated to smoking and accepted as being due to asbestos exposure. The second is squamous, undifferentiated, and small-cell cancer arising in proximal airways, certainly related to smoking but only doubtfully related to asbestos. Perhaps wisely, the council makes no attempt to distinguish between these and recommends prescription irrespective of type. Most authorities accept that the risk of lung cancer is increased only when there has been heavy exposure to dust. Reasonable estimates of exposure may be made for people working in circumscribed places such as asbestos factories, but this may be impossible for, say, shipyard workers or engineers with intermittent exposure in various jobs, particularly in the distant past.

Faced by this difficulty the council has made an ingenious proposal that the presence of other indicators of asbestos exposure should justify certification. It recommends prescription when primary cancer of the lung is accompanied by one or more of the following features: asbestosis, bilateral diffuse pleural thickening, and bilateral pleural plaques.

Asbestosis provides clear evidence of heavy exposure, but, though bilateral diffuse pleural thickening and bilateral pleural plaques are linlied with exposure to asbestos, the relation is less definite and more capricious. ${ }^{7}$ Moreover, pleural disease and asbestosis are also poorly correlated, for the former may appear in lightly exposed people such as the wives of asbestos workers and residents in the vicinity of asbestos mines and factories. Given a minimum exposure to dust, the development of pleural calcification, which facilitates the diagnosis of plaques, is probably mainly determined by age, usually taking over 20 years from the first exposure. ${ }^{8} 9$ Only some $15^{\circ}$ of plaques are detectable during life, ${ }^{10}$ but this proportion might be higher if oblique $x$ ray views were used in addition to the routine ones. ${ }^{11}$ Hence probably the people who are certified during life will not be all those who have plaques but only the minority in whom they are demonstrable. The case for necropsies in people who have had industrial exposure to asbestos and die of lung cancer is clear.

The council's aim has been to identify people with sufficient exposure to dust to justify certification if they develop lung cancer. Workable regulations are difficult to devise, but the proposals favour those with pleural $x$ ray shadows which may be the result of light exposure in the distant past and discriminate against those with much heavier exposure who, for unknown reasons, do not develop pleural lesions or have not had time to do so. The council has decided against specifying a duration and degree of exposure as a qualifying condition because it considers this to be arbitrary and lacking in scientific validity. Even so, the criteria of pleural lesions that it proposes are probably a less than satisfactory index and, though the extension of prescription will be welcomed-even if it requires legislation-probably many will find that the details of the proposals which are now before the Secretary of State for Health are unsatisfactory.

D DAvies

Consultant Chest Physician

City Hospital,

Nottingham NG5 1PR 